\title{
ENXERTIA DE FRUTEIRA-PÃO EM FUNÇÃO DA IDADE DO PORTA-ENXERTO'
}

\author{
ALBERICO RAIMUNDO DA SILVA SANTANA², ANA CRISTINA VELLO LOYOLA DANTAS ${ }^{3}$ \\ PAULO CÉSAR LEMOS DE CARVALHO ${ }^{4}, \mathrm{KELLY} \mathrm{DE} \mathrm{SOUZA} \mathrm{SANTOS}^{5}$
}

RESUMO- A fruteira-pão (Artocarpus altilis var. apyrena) é uma Moraceae de alto valor nutritivo, com ampla distribuição no Brasil. O tipo sem sementes é comumente propagado por estaca de raiz, processo geralmente lento. $\mathrm{O}$ trabalho objetivou avaliar o método da enxertia para propagação de fruteira-pão em função da idade do porta-enxerto. Os porta-enxertos foram obtidos de fruteira-pão $A$. altilis com sementes, e o método de enxertia empregado foi o de garfagem de topo em fenda cheia. O delineamento experimental foi o inteiramente casualizado, com quatro tratamentos (constituídos por porta-enxertos de dois, quatro, seis e oito meses de idade), cinco repetições e 10 plantas por parcela. Foram avaliados o crescimento dos porta-enxertos, a partir do diâmetro do caule, e a altura da planta, e, após a enxertia, as porcentagens de pegamento aos 30 dias e de sobrevivência dos enxertos, número de brotos e de folhas do enxerto e o comprimento do maior broto, aos 90 dias após a enxertia. A enxertia por garfagem no topo em fenda cheia é viável para produção de mudas de fruteira-pão, proporcionando porcentagem de pegamento entre $76 \%$ e $92 \%$, independentemente da idade do porta-enxerto. No entanto, verificou-se que o percentual de sobrevivência do enxerto (72\%) com os porta-enxertos com quatro meses e o diâmetro médio do caule de 10,52 mm foram superiores aos das demais idades. Houve pouca influência da idade do porta-enxerto para o número de brotos e de folhas, porém porta-enxertos com oito meses proporcionaram maior comprimento de broto.

Termos para indexação: Artocarpus altilis, garfagem, propagação.

\section{GRAFTING OF BREADFRUIT IN RELATION TO ROOTSTOCKS AGE}

\begin{abstract}
The study was conducted at the Federal University of Bahia Reconcavo in the municipality of Cruz das Almas, Bahia, Brazil, with the objective of evaluating the effect of the age of rootstock on the method of propagation by grafting. The rootstocks used were obtained from breadfruit tree seeds. A. altilis variety seminifera and grafting method used was the grafting of top cleft when the rootstocks had two, four, six and eight months old. The experimental design was completely randomized with four treatments, five replicates of ten plants per experimental unit. It was evaluated the growth of rootstocks from the stem diameter and plant height, and after grafting was evaluated percentage of fixation, percentage of graft survival at 30 days and number of shoots, number of leaves and graft length of the longest shoot at 90 days. Cleft graft of the top is viable for seedling production of breadfruit. It was found that the percentage of success of the graft to the rootstock four months were higher than other age groups, with $92 \%$ of fixation, $72 \%$ survival with stem diameter of $10.52 \mathrm{~mm}$. There was little influence of age of rootstock on the number of buds and leaves, but rootstocks eight months of bud length increased.
\end{abstract}

Index terms: Artocarpus altilis, cleft grafting, propagation.

\footnotetext{
1(Trabalho 391-13). Recebido em: 15-10-2013. Aceito para publicação em: 08-08-2014.

${ }^{2}$ Engenheiro Agrônomo, Mestre em Recursos Genéticos Vegetais, Universidade Federal do Recôncavo da Bahia. E-mail: albericoraimundo@yahoo.com.br

${ }^{3}$ Professor Associado, Centro de Ciências Agrárias, Ambientais e Biológicas, Universidade Federal do Recôncavo da Bahia. E-mail: acloyola@ufrb.edu.br

${ }^{4}$ Professor Adjunto, Centro de Ciências Agrárias, Ambientais e Biológicas, Universidade Federal do Recôncavo da Bahia. E-mail: pclemos@ufrb.edu.br

${ }^{5}$ Graduanda em Agronomia, Bolsista PIBIC/CNPq, Centro de Ciências Agrárias, Ambientais e Biológicas da Universidade Federal do Recôncavo da Bahia. E-mail: kelly_agroufrb@yahoo.com.br
} 


\section{INTRODUÇÃO}

A espécie Artocarpus altilis (Parkinson) Fosberg, comumente conhecida como fruteira-pão, é originária das ilhas da Oceania. É uma planta versátil, em que todas as suas partes (raízes, folhas, frutos e látex) podem ser utilizadas na medicina caseira. Como essência florestal, seu aproveitamento é integral. A madeira é de peso leve, flexível, considerada resistente aos insetos e relativamente fácil de trabalhar, e pode ser usada principalmente para forro, portas, marcenaria ou para certos tipos de instrumentos musicais, canoas pequenas, para esculpir estátuas, tigelas e outros objetos, e constitui também madeira de boa qualidade para fabricação de carvão. Na Oceania, esta espécie é um dos principais componentes de sistemas agroflorestais que ajudam a prevenir a erosão e a degradação do solo. A maceração da casca dos ramos novos ou do caule de plantas jovens possibilita a extração de fibras, que são utilizadas na fabricação de cordas e esteiras. As folhas e as infrutescências têm certo valor forrageiro, e as folhas também são usadas para envolver comidas para cozinhar em fornos a lenha. A semente pode ser consumida assada ou cozida (DEIVANAI; SUBHASH, 2010).

O valor alimentício do fruto reveste-se de grande importância, principalmente para as populações de baixa renda, que têm neste alimento uma alternativa para suplementação alimentar, podendo ser consumido cozido e, às vezes, assado, quando maduro, e processado em forma de farinha ou goma, e polvilho pode substituir parcialmente a farinha de trigo, em pão, massa e produtos de lanche (JONES et al., 2011).

A fruteira-pão tem ampla adaptação no Brasil, porém é cultivada em pequena escala, desde o Estado de São Paulo até o extremo norte do País, desenvolvendo-se melhor nas regiões baixas e chuvosas (CALZAVARA, 1987). É bastante frequente em quintais agroflorestais da Amazônia e em pomares domésticos da faixa litorânea da Bahia, Paraíba, Alagoas, Sergipe, Pernambuco e Ceará (SACRAMENTO et al., 2009).

A espécie $A$. altilis (Park.) possui dois tipos de variedades: a variedade sem sementes, chamada de apirena, e a com sementes, conhecida como var. seminífera, morfologicamente semelhantes.

Para auxiliar na conservação, manejo e expansão comercial, é necessário o aperfeiçoamento e a recomendação de técnicas de propagação assexuada para essa espécie, especialmente para as cultivares sem semente. A propagação vegetativa da fruteirapão através de estacas de raiz é um método bastante utilizado pelos agricultores, porém é um processo lento, principalmente quando se necessita de grande quantidade de mudas, e envolve vários problemas para o cultivo e a distribuição de cultivares, pelo limitado número de raízes disponíveis a partir de uma árvore individual. Outras técnicas têm sido mencionadas para a propagação da fruteira-pão sem sementes, a exemplo da alporquia e da enxertia (RAGONE, 2006).

A propagação por meio de enxertia foi realizada utilizando como porta-enxerto outras espécies de Moraceae, como A. heterophyllus (jaqueira), A. elastica e A. camansi. Nandwani e Kuniyuki (2005) obtiveram pegamento superior a $80 \%$ e bom desenvolvimento das plantas em campo, a partir da enxertia lateral em portaenxertos produzidos por estacas e brotos de raízes de variedades locais de fruteira-pão da Micronesia, após um ano, quando as plantas estavam enraizadas, vigorosas e estabelecidas no solo. Medagoda e Chandrarathna (2007) realizaram a enxertia sobre porta-enxerto de $A$. camansi com idade de 30; 45 e 60 dias, obtendo melhores resultados em porta-enxertos com 45 dias.

A enxertia é, frequentemente, utilizada na propagação de espécies frutíferas, pois possibilita a união de mais de um genótipo, combinando as características desejáveis de ambos em uma planta composta (HARTMANN et al., 2010), e tem objetivos diversos, como a preservação de plantas, o melhoramento genético e a produção comercial.

A produção do porta-enxerto é uma das etapas fundamentais na formação de mudas de fruteiras de qualidade, sendo que a idade do porta-enxerto pode influenciar no pegamento dos enxertos, devendo haver uma compatibilidade entre o porta-enxerto e o enxerto para o sucesso na enxertia. A enxertia precoce pode trazer diversas vantagens, como diminuição do volume do substrato, melhor aproveitamento do espaço no viveiro e redução do custo de produção de mudas (LEMOS et al., 2010).

Considerando a importância do sucesso da propagação para a multiplicação e a conservação de tipos superiores, e consequentemente para o estimular o cultivo da espécie, esta pesquisa teve por objetivo avaliar o método da enxertia por garfagem de topo em fenda cheia, em fruteira-pão sem semente, sobre porta-enxerto de $A$. altilis, variedade seminífera com diferentes idades. 


\section{MATERIAL E MÉTODOS}

O experimento foi realizado em viveiro do campo experimental I do Centro de Ciências Agrárias, Ambientais e Biológicas da Universidade Federal do Recôncavo da Bahia, no município de Cruz das Almas-BA. O período do experimento foi de maio de 2011 a abril de 2012, envolvendo o período da semeadura das sementes do porta-enxerto à finalização da tomada de dados da enxertia. Os dados meteorológicos, observados e registrados nos períodos da enxertia, relativos à temperatura e à umidade relativa, encontram-se na Tabela 1.

Para a formação dos porta-enxertos, foram utilizadas sementes de fruteira-pão da variedade seminífera provenientes de frutos maduros coletados na Embrapa Amazônia Oriental, semeadas na mesma época, em sacos de polietileno preto $(20 \mathrm{~cm} \mathrm{x} 40$ $\mathrm{cm}$ ) com capacidade para $8 \mathrm{~L}$, contendo o substrato composto de duas partes de solo Latossolo Amarelo álico coeso ( $\mathrm{pH}$ de 4,7, quantidade de fósforo de 13 $\mathrm{mg} \mathrm{dm}{ }^{-3}$, potássio de $0,12 \mathrm{cmol} \mathrm{dm}^{-3}$, cálcio mais magnésio de $0,90 \mathrm{cmol} \mathrm{dm}^{-3}$, índice de saturação de base de $31 \%$ e teor de matéria orgânica de $11,28 \mathrm{~g} \mathrm{~kg}^{-}$ $\left.{ }^{1}\right)$ e uma parte de esterco curtido bovino, adicionandose $50 \mathrm{~g}$ de $\mathrm{KCl}, 200 \mathrm{~g}$ de calcário dolomítico e $130 \mathrm{~g}$ de $\mathrm{P}_{2} \mathrm{O}_{5}$ para cada $\mathrm{m}^{3}$ do substrato homogeneizado. A umidade do substrato foi mantida com regas sempre que necessário.

A enxertia da fruteira-pão foi realizada em porta-enxertos com idades de dois, quatro, seis e oito meses após a emergência, quando os mesmos apresentaram no momento da enxertia uma altura de $29 ; 43 ; 81$ e $102,5 \mathrm{~cm}$, e um diâmetro de 7,4 ; 10,$5 ; 20,5$ e $25,4 \mathrm{~cm}$, respectivamente. A enxertia foi realizada nos meses de julho, setembro e novembro de 2011, e janeiro de 2012.

O método de enxertia utilizado foi a garfagem no topo em fenda cheia, realizado por um único enxertador, com garfos sadios de matrizes de fruteirapão, variedade apirena, provenientes de Cruz das Almas-BA. Os garfos foram retirados no dia da enxertia, com comprimento de $20 \mathrm{~cm}$ e diâmetro compatível com o diâmetro do porta-enxerto, sendo a porção apical eliminada no momento da enxertia. Como houve um crescimento exagerado do portaenxerto, a enxertia foi realizada à altura de $15 ; 20 ; 30$ e $50 \mathrm{~cm}$ do colo da planta, respectivamente, para dois, quatro, seis e oito meses após a emergência. Após a enxertia, os garfos e a região da enxertia foram protegidos com saco plástico transparente, de forma a possibilitar a formação de uma câmara úmida. A proteção plástica foi retirada após a verificação do aparecimento de folhas.
O ensaio foi conduzido no delineamento inteiramente casualizado, com quatro tratamentos (idades dos porta-enxertos), cinco repetições e 10 plantas por parcela, totalizando 200 plantas. A disposição dos sacos com as plantas no viveiro foi em fileiras duplas, distanciadas por 1,20 m, e o espaçamento dentro das parcelas foi de $0,40 \mathrm{~m}$ entre as linhas e $0,40 \mathrm{~m}$ entre as plantas. As características referentes à enxertia avaliadas foram: pegamento, verificando-se a quantidade de enxertos com brotos aos 30 dias após a enxertia (em porcentagem); sobrevivência dos enxertos, a partir da contagem dos enxertos vivos aos 90 dias após a enxertia (em porcentagem); número de brotos; número de folhas do enxerto e comprimento do maior broto $(\mathrm{em} \mathrm{cm})$, também aos 90 dias após a enxertia.

Os dados foram submetidos à análise de variância, sendo os valores expressos em porcentagem, transformados em arc sen [(raiz $\mathrm{x}+0,5) / 100]$ para atendimento das pressuposições da análise da variância, e as diferenças entre as médias, comparadas pelo teste de Tukey, a 5\% de probabilidade.

\section{RESULTADOS E DISCUSSÃO}

As brotações dos garfos enxertados iniciaramse aos 15 dias após a enxertia, observando-se efeito da idade do porta-enxerto nas variáveis analisadas, com exceção da porcentagem de pegamento (Tabela 2), que aos 30 dias após a enxertia variou de $76 \%$ a $92 \%$, sem diferença estatística (Tabela 3). Apesar de as enxertias terem sido realizadas em diferentes épocas, os dados climáticos apresentados na Tabela 1 revelam que houve pouca variação na umidade relativa e nas mínimas e máximas temperaturas nos períodos da enxertia, e os valores de temperatura registrados ficaram na faixa mencionada como adequadas para o sucesso da enxertia, entre 15 e $30^{\circ} \mathrm{C}$ (HARTMANN et al., 2010).

Em relação à sobrevivência, a enxertia aos quatro meses, quando os porta-enxertos apresentavam diâmetro médio de 10,52 mm, proporcionou 72,0\% de enxertos vivos aos 90 dias após a enxertia, o que foi significativamente superior aos observados com as enxertias realizadas em porta-enxertos com dois, seis ou oito meses de idade, com $36 \%, 30 \%$ e $18 \%$ de sobrevivência, respectivamente (Tabela 3).

A enxertia de fruteira-pão com porta-enxerto de quatro meses de idade já foi mencionada por Rowe-Dutton (1985), porém não foi citado se houve sucesso na sobrevivência dos enxertos. Fonseca (2010), estudando a cultura da jaqueira ( $A$. heterophyllus Lam.), obteve porta-enxertos aptos 
para a enxertia aos quatro meses de idade, com diâmetro do caule variando entre 7,5 e 8,5 mm. Trabalhos têm mostrado que porta-enxertos com diâmetro em torno de $10 \mathrm{~mm}$ são recomendados para enxertia de diversas fruteiras, a exemplo do observado com as culturas do umbuzeiro (GOMES et al., 2010) e pinheira (LEMOS et al., 2010).

A técnica da enxertia só é viabilizada devido à grande capacidade de produção de novas células nas regiões de união das plantas, e na totipotencialidade existente nessas células vegetais. Essa característica faz com que as células, depois de sucessivas mitoses, consigam diferenciar-se em células de tecidos e de vasos condutores, perfazendo uma completa união entre as partes envolvidas na enxertia. $\mathrm{O}$ tipo de garfo pode ajudar a garantir essa união entre o enxerto e o porta-enxerto, lembrando-se de que o fluxo da seiva sempre ocorre a partir da base para a parte superior. Verificou-se que as enxertias realizadas aos dois meses de idade do porta-enxerto apresentaram baixa porcentagem de sobrevivência (Tabela 3 ). Por outro lado, tecidos maduros, mais desenvolvidos, apresentam alto teor de lignina, podendo interferir na hidratação das mudas. Plantas com excesso de lignina são mais sensíveis à desidratação e à morte, e têm menor afinidade fisiológica e anatômica com o garfo (BASTOS et al., 2006). De fato, as garfagens realizadas em porta-enxertos com seis e oito meses de idade, e diâmetro médio de 20 e 25 $\mathrm{mm}$, respectivamente, também apresentaram baixas porcentagens de sobrevivência dos enxertos aos 90 dias após a enxertia (Tabela 3). Malagi et al. (2012) ressaltaram que garfos semilenhosos de maior diâmetro, devido ao seu estado de maior lignificação, contribuem para a redução do pegamento dos enxertos; além disso, à medida que as plantas lenhosas jovens se desenvolvem, a lignificação do caule aumenta, de modo que o sucesso da enxertia é limitado pela dificuldade de cicatrização e pela união cambial do enxerto e do porta-enxerto.

As variáveis números de brotos e de folhas (Tabela 3) também foram influenciadas pela idade do porta-enxerto. Os maiores valores para número de brotos foram obtidos para os garfos com maior diâmetro, média acima de 10,52 mm, utilizados nas enxertias realizadas em porta-enxertos com quatro, seis e oito meses de idade, embora sem diferença significativa entre oito e dois meses. O aparecimento das folhas ocorreu cerca de 30 dias após o brotamento, sendo que não houve diferenças entre porta-enxertos com quatro, seis e oito meses de idade quanto ao número de folhas aos 90 dias após a enxertia (Tabela 3). Quanto ao comprimento do maior broto, as maiores médias foram observadas em porta-enxertos de maior idade (oito meses). Segundo Hartmann et al. (2010), o brotamento depende de diversos fatores, dentre os quais a idade da planta, pois plantas com maior idade possuem raízes mais desenvolvidas e maior quantidade de tecido de reserva, o que auxilia no desenvolvimento dos brotos. Gomes et al. (2010), estudando a garfagem e o diâmetro de porta-enxerto na obtenção de mudas de umbuzeiro, verificaram que o aumento das brotações foi mais evidente nos tratamentos com maior diâmetro do porta-enxerto.

TABELA 1- Data da enxertia em fruteira-pão (Artocarpus altilis) com as respectivas idades (meses) do porta-enxerto, temperaturas mínimas e máximas e umidade relativa. Cruz das Almas-BA.

\begin{tabular}{ccccc}
\hline \multirow{2}{*}{ Idade (meses) } & \multirow{2}{*}{ Enxertia } & \multicolumn{2}{c}{ Temperatura $\left({ }^{\circ} \mathbf{C}\right)$} & \multirow{2}{*}{ Umidade Relativa (\%) } \\
\cline { 3 - 4 } & $07 / 2011$ & 17,01 & 26,67 & 88 \\
$\mathbf{2}$ & $09 / 2011$ & 15,76 & 29,79 & 94 \\
$\mathbf{4}$ & $11 / 2011$ & 17,00 & 28,20 & 90 \\
$\mathbf{6}$ & $01 / 2012$ & 22,00 & 29,80 & 88 \\
$\mathbf{8}$ & &
\end{tabular}

Fonte: INMET (Instituto Nacional de Meteorologia) 
TABELA 2-Resumo da análise de variância para percentagem de pegamento (\%P), 30 dias após a enxertia, porcentagem de sobrevivência dos enxertos $(\% \mathrm{~S})$, número de brotos $(\mathrm{NB})$, número de folhas do enxerto (NF) e comprimento do maior broto (CMB) $(\mathrm{cm})$ aos 90 dias após a enxertia de fruteira-pão (Artocarpus altilis) sobre porta-enxerto de diferentes idades. Cruz das Almas-BA.

\begin{tabular}{ccccccc}
\hline \multirow{2}{*}{$\begin{array}{c}\text { Fonte de } \\
\text { Variação }\end{array}$} & GL & \multicolumn{5}{c}{ Quadrado médio } \\
\cline { 3 - 7 } & & $\% \mathbf{P}$ & $\% \mathbf{S}$ & $\mathbf{N B}$ & $\mathbf{N F}$ & $\mathbf{C M B}$ \\
\hline Idade & 3 & $298,33^{\text {ns }}$ & $2.700,00^{* *}$ & $2,21^{* *}$ & $22,10^{*}$ & $98,98^{* *}$ \\
Resíduo & 16 & 135,00 & 205,00 & 0,36 & 5,05 & 2,38 \\
\hline CV \% & - & 13,91 & 36,71 & 20,24 & 20,26 & 10,21 \\
Média & - & $83,50 \%$ & $39,00 \%$ & 2,97 & 11,09 & $15,11 \mathrm{~cm}$ \\
\hline
\end{tabular}

**; * significativo a 1 e $5 \%$ pelo teste $\mathrm{F}$, respectivamente. ns - não significativo

TABELA 3- Idades (meses), diâmetros do porta-enxerto $(\mathrm{mm})$ e respectivas médias de porcentagem de pegamento $(\% \mathrm{P})$ aos 30 dias após a enxertia, porcentagem de sobrevivência $(\% \mathrm{~S})$, número de brotos $(\mathrm{NB})$, comprimento do maior broto (CMB) (cm) e número de folhas dos enxertos (NF) de mudas de fruteira-pão (A. altilis), 90 dias após a enxertia sobre porta-enxerto de diferentes idades, em Cruz das Almas-BA. 2012.

\begin{tabular}{ccccccc}
\hline $\begin{array}{c}\text { Idade } \\
\text { (meses) }\end{array}$ & $\begin{array}{c}\text { Diâmetro do } \\
\text { porta-enxerto }(\mathbf{m m})\end{array}$ & $\mathbf{\% P}$ & $\mathbf{\% S}$ & $\mathbf{N B}$ & $\mathbf{N F}$ & $\begin{array}{c}\text { CMB } \\
\mathbf{( c m})\end{array}$ \\
\hline $\mathbf{2}$ & 7,36 & $78,0 \mathrm{a}$ & $36,0 \mathrm{~b}$ & $2,0 \mathrm{~b}$ & $8,7 \mathrm{~b}$ & $10,6 \mathrm{c}$ \\
$\mathbf{4}$ & 10,52 & $92,0 \mathrm{a}$ & $72,0 \mathrm{a}$ & $3,6 \mathrm{a}$ & $12,1 \mathrm{ab}$ & $13,2 \mathrm{bc}$ \\
$\mathbf{6}$ & 20,51 & $88,0 \mathrm{a}$ & $30,0 \mathrm{~b}$ & $3,2 \mathrm{a}$ & $13,4 \mathrm{a}$ & $15,5 \mathrm{~b}$ \\
$\mathbf{8}$ & 25,36 & $76,0 \mathrm{a}$ & $18,0 \mathrm{~b}$ & $3,0 \mathrm{ab}$ & $10,1 \mathrm{ab}$ & $21,1 \mathrm{a}$ \\
\hline
\end{tabular}

Médias seguidas pela mesma letra na coluna não diferem entre si, pelo teste de Tukey $(\mathrm{P}<0,05)$.

\section{CONCLUSÕES}

A enxertia por garfagem no topo em fenda cheia é viável para produção de mudas de fruteira-pão.

Existe influência da idade do porta-enxerto na eficiência da enxertia em fruteira-pão, sendo recomendada a enxertia em porta-enxertos com quatro meses de idade, com diâmetro do caule em torno de $10 \mathrm{~mm}$.

\section{REFERÊNCIAS}

BASTOS, D. C.; PIO, R.; SCARPARE FILHO, J. A.; ALMEIDA, L. F. P. de; ENTELMANN, F. A.; ALVES, A. S. R. Tipo de estaca e concentração de ácido indolbutírico na propagação de lichieira. Ciência e Agrotecnologia, Lavras, v. 30, n. 1, p. 97-102, 2006.

CALZAVARA, B. B. G. Fruticultura tropical: a fruta-pão. 6. ed. Belém: Museu Paraense Emílio Goeldi, 1987. 279 p.
DEIVANAI, S.; SUBHASH J. B. Breadfruit (Artocarpus altilis Fosb.) - An underutilized and neglected fruit plant species. Middle-East Journal of Scientific Research, Dubai, v. 6, n. 5, p. 418-428, 2010.

FONSECA, V. J. de A. Caracterização, seleção e propagação vegetativa de genótipos de jaqueira. 2010. 109 f. Tese (Doutorado em Fitotecnia) - Centro de Ciências Agrárias, Ambientais e Biológicas, Universidade Federal do Recôncavo da Bahia, Cruz das Almas, 2010.

GOMES, W. de A.; MENDONÇA, R. M. N.; SOUZA, E. P. de; ESTRELA, M. A.; MELO, V. e S.; SILVA, S. de M.; SOUZA, A. P. de. Garfagem e diâmetro de porta-enxerto na obtenção de mudas de umbuzeiro do acesso laranja. Revista Brasileira de Fruticultura, Jaboticabal, v. 32, n. 3, p. 952-959, 2010. 
HARTMANN, H. T.; HUDSON, T.; KESTER, D.E.; DALE, E. K.; DAVIES JR., F.T.; GENEVE, R. L. Plant propagation: principles and practices. New Jersey: Prentice-Hall, 2010. 880 p.

JONES, A. M. P.; RAGONE, D.; AIONA, K.; LANE, W. A.; MURCH, S. J. Nutritional and morphological diversity of breadfruit (Artocarpus, Moraceae): Identification of elite cultivars for food security. Journal of Food Composition and Analysis, London, v. 24, p. 1.091-1.102, 2011.

LEMOS, E. E. O. P. de; SALVADOR, T. de L.; SANTOS, M. Q. C. dos; REZENDE, L. de P.; SALVADOR, T. de L.; LIMA, H. M. A. Produção de porta-enxertos em tubetes e enxertia precoce da pinheira (Annona squamosa L.). Revista Brasileira de Fruticultura, Jaboticabal, v. 32, n. 3, p. 865-873, 2010.

MALAGI, G.; CITADIN, I.; SCARIOTTO, S.; WAGNER JÚNIOR, A.; SACHET, M. R. Enxertia interespecífica de jabuticabeira: influência do tipo de garfo. Ciência Rural, Santa Maria, v. 42, n. 2, p. 221-224, 2012.

MEDAGODA, I.; KUMARI CHANDRARATHNA, W. M. C. J. Grafting of breadfruit (Artocarpus altilis) using breadnut (Artocarpus camansi) as root stock. Acta Horticulturae, Wageningen, v.757, p.149-152, 2007.
NANDWANI, D.; KUNIYUKI, A. H. Grafting and improvement of breadfruit production in Micronesia. Acta Horticulturae, Wageningen, v.694, p.307-310, 2005.

RAGONE, D. Breadfruit. Artocarpus altilis (Parkinson) Fosberg. Promoting the conservation and use of underutilized and neglected crops. 10. Rome: International Plant Genetic Resources Institute, $2006.77 \mathrm{p}$.

ROWE-DUTTON, P. Artocarpus altilis - breadfruit. In: GARNER, R.J.; CHAUDHRI, S.A. The propagation of tropical fruit trees. Maidstone: Commonwealth Bureau of Horticulture and Plantation Crops, 1985. p.248-268.

SACRAMENTO, C.K.; LEITE, J.B.V.; CARVALHO, J.E.U.; NASCIMENTO, W.M.O. Fruta-pão. In: SANTOS-SEREJO, J.A.; DANTAS, J.L.L.; SAMPAIO, C.V.; COELHO,Y.S. (Org.). Fruticultura tropical: espécies regionais e exóticas. Cruz das Almas: Embrapa, 2009. p.187-200. 